\title{
Lead poisoning in a group of demolition workers
}

\author{
B. C. CAMPBELL 1 AND A. W. BAIRD 2
}

From the ${ }^{1}$ Department of Materia Medica, Stobhill Hospital, Glasgow G21 3UW, and the ${ }^{2}$ Employment Medical Advisory Service, Portcullis House, India Street, Glasgow G2 4PH

ABSTRACT The incidence of lead poisoning in industry has fallen dramatically since the beginning of the twentieth century. This reduction has been partly attributable to increased awareness, improved ventilation and hygiene facilities, and technical changes which have allowed other substances to replace lead, but improved medical surveillance of workers exposed to lead in certain defined industries has also been important. Not all industries where lead exposure can occur are at present covered by specific regulations dealing with lead, however. We report the diagnosis and treatment of eleven oxyacetylene metal burners involved in the demolition of a railway station, who rapidly developed frank lead poisoning. The most suitable measurements to employ in evaluating such a population are considered. The selection, based on blood lead and haemoglobin measurements, of those who should receive further treatment is discussed. Symptoms were found to be more nearly related to indices of effect or toxicity of lead than to indices of exposure or absorption. The effects of chelation therapy upon symptoms, blood lead, haemoglobin and urinary porphyrins are recorded. The need for careful follow-up is illustrated.

Improved surveillance, tighter control and technical changes have brought about a dramatic reduction in the incidence of industrial lead poisoning in the last 70 years, but quite serious outbreaks may still occur in industries where periodic inspection is not a statutory requirement. In the area of Clydeside are located many of the industries which have in the past given rise to lead exposure, including shipbuilding and shipbreaking, lead smelting, battery and paint manufacture, automobile manufacture and printing, and a few cases of poisoning arise each year from such sources. This report, however, relates to a group of 12 metal burners engaged in demolition all of whom showed biochemical evidence of excessive lead exposure, and all but one of whom required admission to hospital for treatment of lead poisoning.

\section{How the problem arose}

St. Enoch Station was one of the main Glasgow railway termini but as a result of rationalisation schemes by British Rail was closed as a station in 1968 and thereafter used as a car park. By 1975, however, it was felt that the roof structure would become an increasing hazard without expensive maintenance and should be demolished. This presented a problem, as metal beams coated with many layers of paint had

Received for publication 28 January 1977

Accepted for publication 24 February 1977 to be cut up into short sections in situ using oxyacetylene equipment. The paint coating the ironwork was subsequently shown to contain 20 per cent by weight of lead as well as $0 \cdot 1$ per cent by weight of cadmium. Respirators were made available but were unsatisfactory on a number of grounds; principally they were cumbersome and interfered with vision which could prove critical when working at heights of up to $24 \mathrm{~m}$, and they were discarded.

\section{How the problem was discovered}

One of the workers employed on metal burning presented to a city hospital and was notified as a case of lead poisoning. Following this, one of us screened the entire work force for evidence of excessive lead exposure. The point at which 'evidence of lead exposure' becomes 'evidence of lead poisoning' is necessarily arbitrary; certain biochemical changes, notably depression in the activity of the enzyme $\delta$ aminolevulinic acid dehydrase (ALAD), are induced by quite low levels of lead. Lane et al. (1968) believed that a diagnosis of lead poisoning should be based on clinical as well as biochemical grounds. Gibson et al. (1968) studied 100 lead workers from different industries and concluded that haemoglobin and urinary porphyrin measurements were those of most value in screening workers at risk.

In our investigacion blood was obtained for 
measurement of lead and haemoglobin, and urine for a quantitative measurement of $\delta$-aminolevulinic acid (ALA) and a semiquantitative measurement of coproporphyrin. Blood lead was measured by atomic absorption spectrophotometry using a Perkin Elmer 306 with HGA 72 flameless atomiser by the method of Meredith et al. (1977).

The workers were screened several times and the findings on two of these occasions are shown in Figs. 1a and $b$ (see also Fig. 6). The overall deterioration in the 6-week interval can be observed. Many of
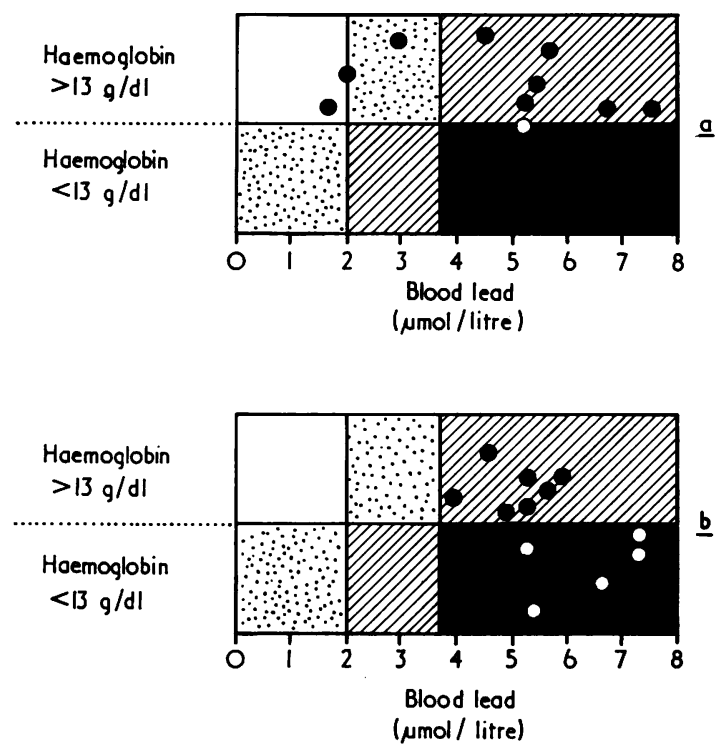

Fig. 1a and 1b Blood lead and haemoglobin measurements from burners demolishing St. Enoch Station, at two points in time six weeks apart showing a deteriorating situation. For interpretation see Fig. 6.

the workers were found to have blood lead levels in excess of $3.8 \mu \mathrm{mol} / 1\left(80^{\circ} \mu \mathrm{g} / 100 \mathrm{ml}\right)$, which is the upper limit acceptable in an industrially exposed population, with increased urinary porphyrin excretion and depression of haemoglobin. Those found to have blood leads in excess of $5 \cdot 7 \mu \mathrm{mol} / 1(120 \mu \mathrm{g} / 100$ $\mathrm{ml}$ ) or a lead level between 3.8-5.7 $\mu \mathrm{mol} / \mathrm{l}$, accompanied by a haemoglobin of less than $13 \mathrm{~g} / \mathrm{dl}$, or a falling haemoglobin on successive screening, were referred to hospital for further investigation and treatment. At the same time respirators of an improved pattern were issued to the work force and the need for personal hygiene was stressed.

\section{Hospital management}

In addition to the worker initially presenting to another hospital, 11 were seen as outpatients and 10 of them were admitted for treatment. Their mean blood lead on screening at work had been $6.7 \mu \mathrm{mol} / 1$. Although about two weeks had elapsed between this screening result and their admission to hospital, the mean period actually off work before admission was $5 \cdot 1$ days. During the interval the mean blood lead had fallen to $5 \cdot 1 \mu \mathrm{mol} / 1$ (Fig. 2). This fall is statisti-

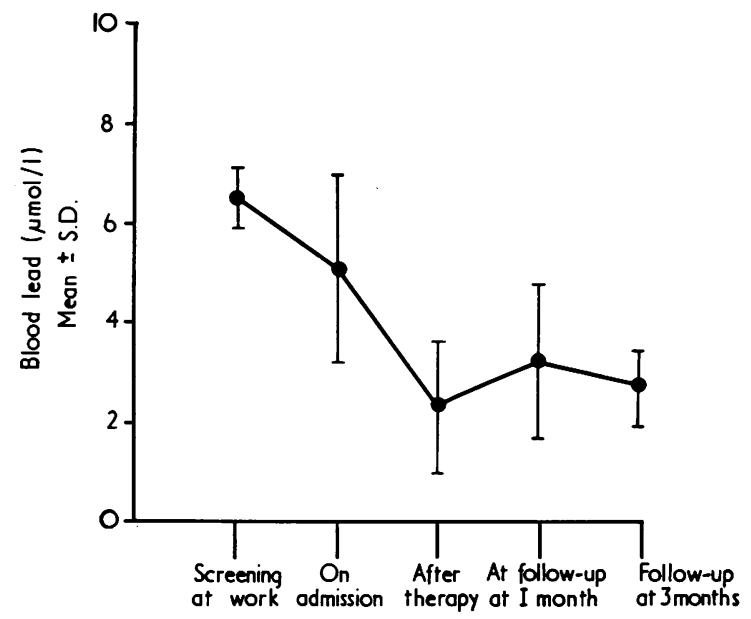

Fig. 2 Blood lead values at intervals during the management of the lead-poisoned demolition workers.

cally significant ( $P<0.01$, using Student's ' $t$ ' test for paired values). In addition to satisfying the biochemical criteria for referral, all eleven had symptoms. The presenting features are shown in Fig. 3. In general, these are the features classically associated with lead poisoning but it is worth noting that five of the subjects complained of pleuritic chest pain, clearly distinguished from abdominal colic by those who had both complaints.

As well as having an elevated blood lead, all the subjects were anaemic (haemoglobin less than 13 $\mathrm{g} / \mathrm{dl}$ ), the mean haemoglobin level being $11 \mathrm{~g} / \mathrm{dl}$. Although in lead poisoning the degree of anaemia is often mild, one subject had an initial haemoglobin level of $8.7 \mathrm{~g} / \mathrm{dl}$, which subsequently fell to $7.8 \mathrm{~g} / \mathrm{dl}$, necessitating transfusion. Six of the ten admitted showed marked basophilic stippling on their blood film.

Urinary ALA and coproporphyrin levels were elevated for the group as a whole, the mean ALA being $313 \mu \mathrm{mol} / 1$ (upper limit of normal $30 \mu \mathrm{mol} / 1$ ), and the mean coproporphyrin $1050 \mathrm{nmol} / 1$ (normal not more than $320 \mathrm{nmol} / \mathrm{l})$. In addition, porphobilinogen levels were raised in the urine of six of the nine subjects in whom this was measured, and the 


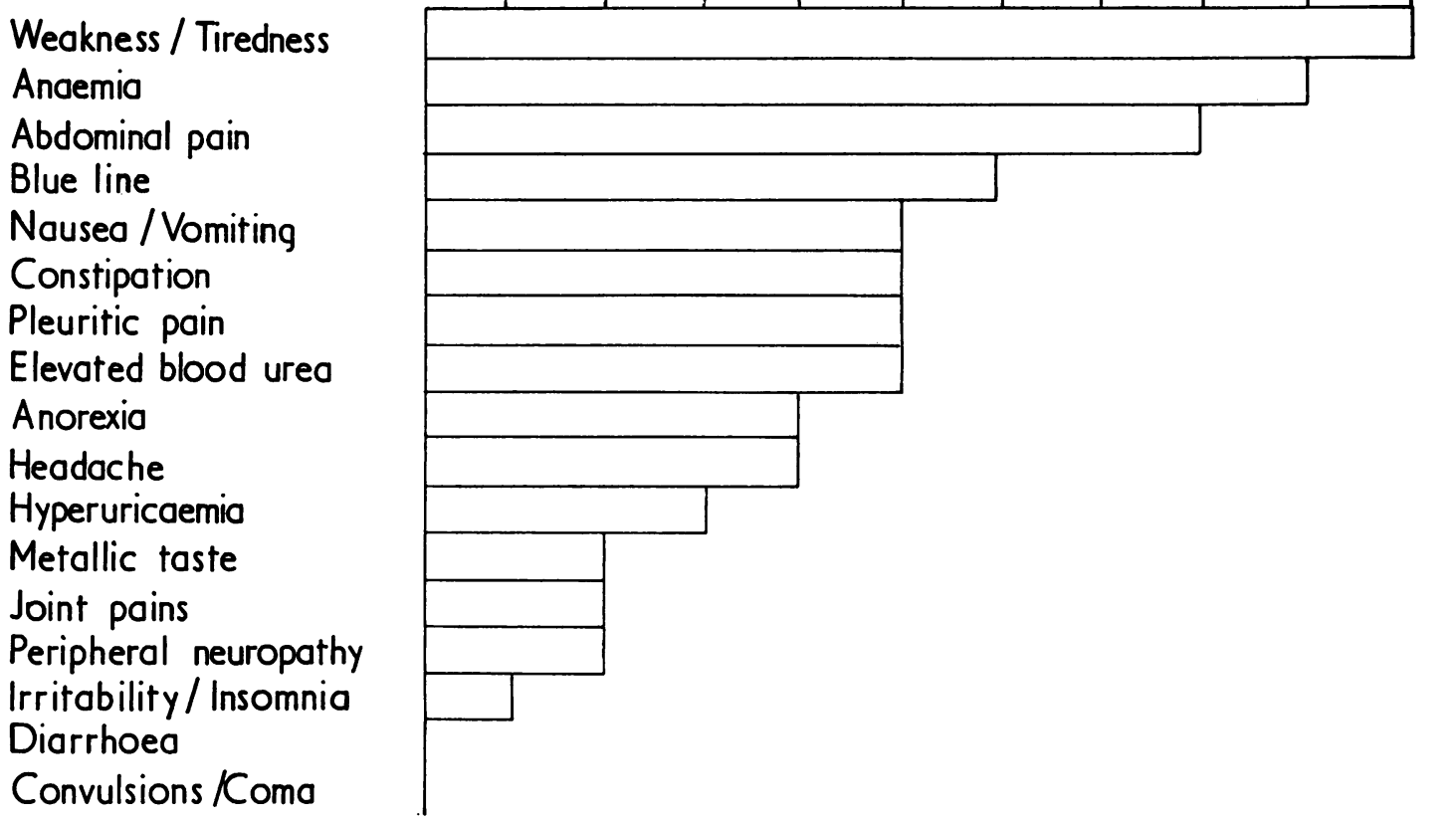

Fig. 3 The incidence of clinical features in the demolition workers referred to hospital.

mean erythrocyte protoporphyrin was nearly ten times the normal upper limit at $6050 \mathrm{nmol} / \mathrm{l}$. However, two subjects who had coproporphyrin within normal limits, in one of whom ALA was also normal, had moderate symptoms, an elevated blood lead and were anaemic. Mean blood urea level was elevated at $7 \cdot 2 \mu \mathrm{mol} / \mathrm{l}$, but the blood creatinine and urate levels were normal.

It proved difficult to relate severity of symptoms to any single biochemical measurement. In an attempt to clarify this point a crude symptom score of one point was given for each symptom which could be related to lead poisoning. Scores from 1 to 7 were obtained. These scores were then compared with the initial blood lead, urinary lead, urinary ALA, coproporphyrin and porphobilinogen levels, and later with lead excreted in the urine over five days in response to chelation therapy. This symptom score was not found to be related to any of these factors in a statistically significant way, although the correlation was particularly poor with initial blood lead and urinary lead, and much more nearly significant with total lead excreted and urinary porphyrins.

In this small group, indices of severity of lead exposure, namely blood lead and chelatable lead levels, were not related in a statistically significant way to indices of biochemical effect, for example, urinary ALA and coproporphyrin or erythrocyte protoporphyrin levels.

In summary, all those admitted had a history of lead exposure, symptoms consistent with that history, increased blood lead, anaemia, and most had characteristic abnormalities of the urinary ALA and coproporphyrin excretion. It was felt, therefore, that all merited active therapy. The eleventh subject referred to hospital was an exception, as he had barely satisfied the criteria for referral and had been off work for several weeks; subsequently it was found that his symptoms had largely resolved and his haemoglobin level had become normal. Therefore, although his blood lead level remained elevated at $4.2 \mu \mathrm{mol} / 1$, therapy was felt to be unnecessary in this case. Those admitted received the chelating agent calcium disodium edetate in a divided daily dose of $80 \mathrm{mg} / \mathrm{kg}$ body weight, made up in $100 \mathrm{ml}$ of $5 \%$ glucose (dextrose) solution by twice-daily intravenous infusion for five days in the first instance.

\section{Results}

In each case there was symptomatic improvement, although there were three instances of a transient 
exacerbation of abdominal pain during the course of chelation. It was found that this pain could be quickly relieved by the intravenous administration of $10 \mathrm{mg}$ of calcium gluconate. Only one subject, who had been the most severely affected in terms of blood lead elevation and anaemia, required a further course of chelation therapy at this stage because of continuing symptoms and a blood lead level still elevated at $5.5 \mu \mathrm{mol} / 1$ following the initial course.

The mean total lead excreted in the urine over the five days of chelation was $235 \mu \mathrm{mol}(49 \mathrm{mg})$, and there was a fall of the mean blood lead to $2.4 \mu \mathrm{mol} / 1$ (Fig. 2). Urinary porphyrins also fell, the ALA from a mean before therapy of $313 \mu \mathrm{mol} / 1$ to $11 \mu \mathrm{mol} / \mathrm{l}$, and the coproporphyrin from $1050 \mathrm{nmol} / \mathrm{l}$ to 174 $\mathrm{nmol} / \mathrm{l}$. In four of the subjects, 24-hour urine collections were obtained during the five days of chelation therapy and daily excretion of ALA and coproporphyrin measured. Figs. 4 and 5 show the rapid return

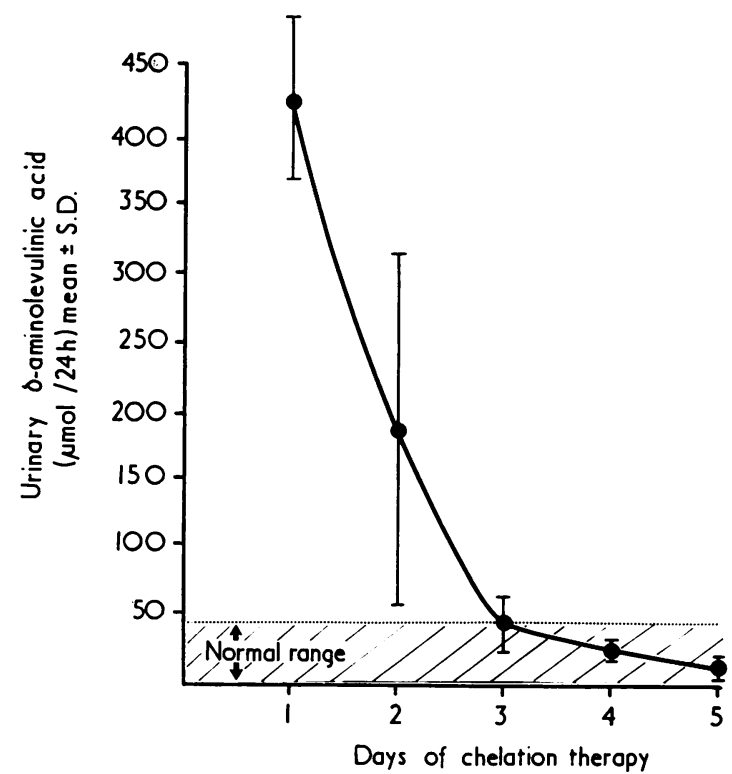

Fig. 4 Urinary ALA excretion during chelation therapy.

to normal of these indices in the first three days of therapy. Despite the apparent marked improvement in the activity of certain enzymes in the haem biosynthetic pathway, which these urinary findings reflect, there was no significant change in haemoglobin or erythrocyte protoporphyrin levels immediately following therapy. The elevated blood urea fell to normal. After completion of chelation therapy, all subjects professed improvement or resolution of their symptoms. They were discharged

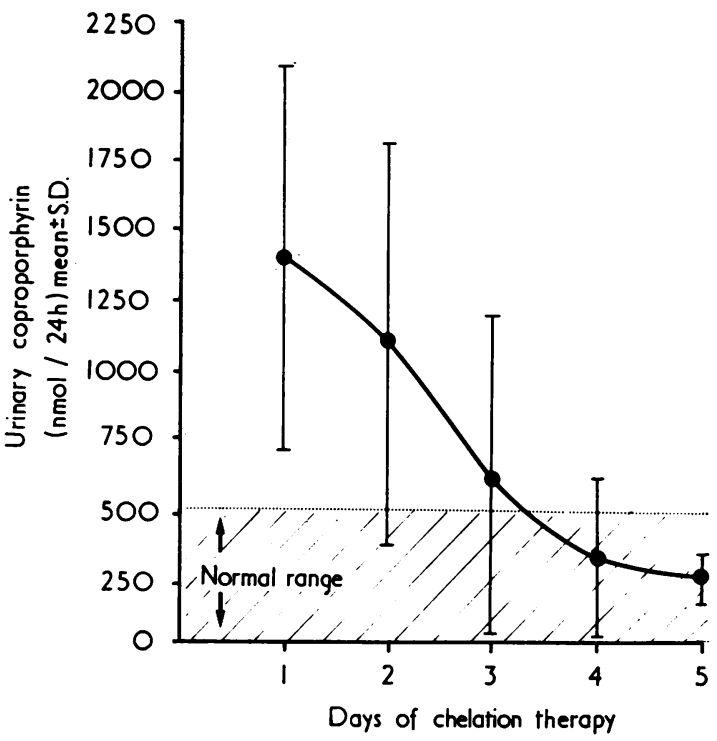

Fig. 5 Urinary coproporphyrin excretion during chelation therapy.

from hospital with strong advice to avoid further exposure to lead for the time being.

With one exception, all were seen about one month later as outpatients. By that time in every case, the blood lead level had risen again to a new mean of 3.2 $\mu \mathrm{mol} / 1(65 \mu \mathrm{g} / 100 \mathrm{ml})$ in the absence of further industrial exposure. Generally this was not accompanied by fresh symptoms, although most continued to complain in a non-specific way of a general reduction in well-being. In one case, however, the blood lead had risen quite dramatically from $2.2 \mu \mathrm{mol} / \mathrm{l}$ $(46 \mu \mathrm{g} / 100 \mathrm{ml})$ following therapy to $5.8 \mu \mathrm{mol} / \mathrm{l}(123$ $\mu \mathrm{g} / 100 \mathrm{ml})$. This patient complained of abdominal pain of much greater severity than he had experienced at the time of his original admission, and required a further chelation course. The remainder had blood lead levels which, while elevated compared with the immediate post-chelation measurements, were within the industrial limit and had a stable or rising haemoglobin.

The patients have been followed up at frequent intervals. Some had not returned to work at three months, others had changed their jobs, and the remainder had returned to similar work but in better conditions with much greater awareness of the need for personal vigilance. In each case there has been continuing symptomatic improvement and although the mean blood lead of the group was elevated after one month, it had fallen again to $2.8 \mu \mathrm{mol} / 1$ (30 $\mu \mathrm{g} / 100 \mathrm{ml}$ ) at three months. Blood lead in individuals improved at three months whether they had returned to work with lead or not. Further follow-up, 
however, suggests that those who continue to be exposed to lead have a higher blood lead level than those who find other employment.

\section{Discussion}

The present century has seen a reduction, as dramatic as it is welcome, in the incidence of industrial lead poisoning. Much tighter control, stricter legislation, technical advance and periodic inspection of workers in these industries, which is required by statute, has meant that lead poisoning is seldom encountered in more than one or two individuals working in such industries at any one time. Nevertheless, sporadic occurrences of the kind described may occur in industries not covered by the statutory regulations, industries indeed which may give rise to no cases of lead poisoning for years until a particular piece of work is undertaken. In our experience this may occur particularly in demolition and scrap metal work.

When considering a group of lead-exposed workers, the first problem encountered is to decide at which point further action, apart from continued surveillance, is required. It is a simple matter to apply an arbitrarily defined upper limit of acceptability of blood lead for example, and to require workers whose level exceeds that limit to be laid off. There is, however, a fairly large interlaboratory error in the measurement of blood lead, although reproducible results are obtained within laboratories which carry out large numbers of estimations. Many workers exposed to lead will have blood lead levels near the upper limit, while others may be by chance over the limit on one estimation. To consider this factor alone, therefore, would often disrupt industry unnecessarily.

Erythrocyte protoporphyrin levels can be measured easily enough now for this to be given consideration as a screening test. Its main disadvantage is that it is raised not only in lead poisoning but in several of the anaemias, including iron deficiency anaemia. These conditions, especially iron deficiency anaemia, are sufficiently common to limit the value of erythrocyte protoporphyrin as a screening test. It is also raised in erythropoietic protoporphyria but this is a rare condition and can be discounted in screening.

We agree with Gibson et al. (1968) that urinary ALA and coproporphyrin measurements are reliable indices of the toxic effect of lead, but the collection of 24-hour specimens of urine, which is necessary for accurate quantitative measurement of ALA and coproporphyrin, and indeed the measurements themselves, are too time-consuming. Semiquantitative estimates applied to random voidings of urine are of value only as a supplementary screening procedure.

Haemoglobin estimation clearly falls far short of being specific in itself and, in the experience of some investigators, is rather poorly correlated with other indices (Williams, 1966). Nevertheless, it is a readily measurable index of lead effect and we consider that by measuring blood lead and haemoglobin a reasonable picture of lead exposure and lead effect can be obtained. Our interpretation of these data is summarised in Fig. 6. On this basis, absence of evidence of excessive lead exposure/effect means that it is sufficient merely to continue to monitor blood lead and haemoglobin at intervals. Evidence of excessive or dangerous exposure merits further investigation both of the subject and of his environment. The presence of symptoms will also influence the decision.

When the 11 subjects were referred to hospital, a striking finding was the apparent significant fall in their blood lead levels between the time of their

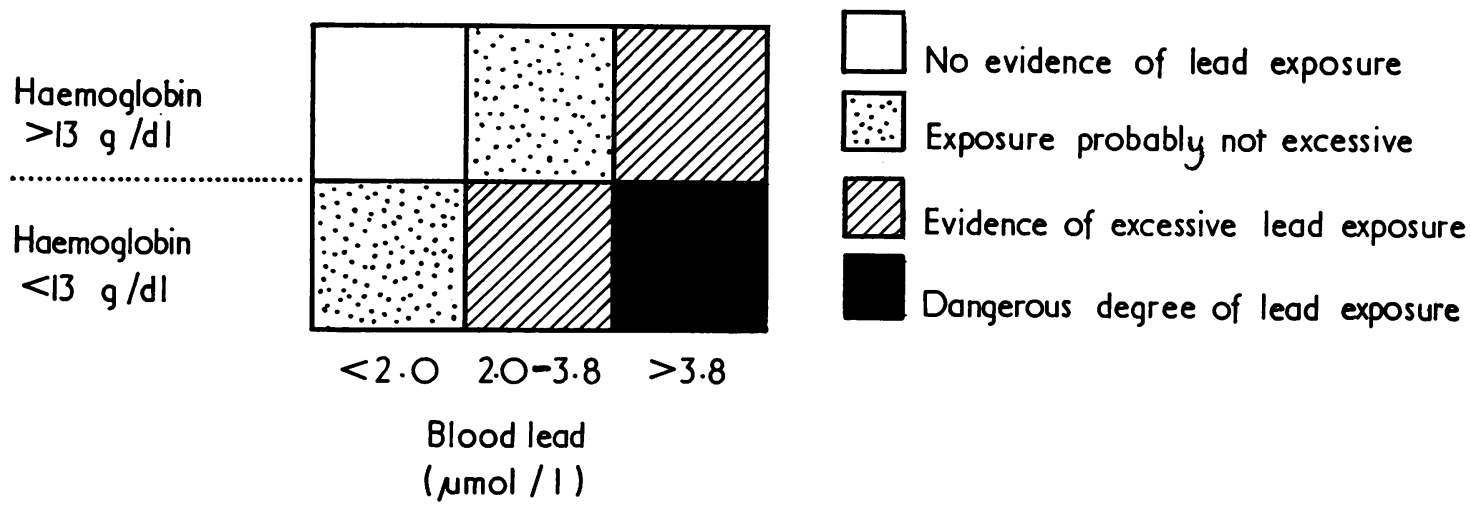

Fig. 6 Guide to degree of lead exposure from blood lead and haemoglobin measurements: a basis for assessing the severity of lead exposure and toxicity in industry. 
screening and the time of their admission. This had occurred despite their absence from the toxic environment for only a few days. The change was unaccompanied by any obvious improvement in wellbeing. A possible explanation is that different laboratories were involved in the measurement on screening and following hospital referral. One subject whose blood lead was measured by the same laboratory throughout did not display this initial fall. The results of this laboratory are monitored by the National Quality Control Scheme at the Queen Elizabeth Hospital, Birmingham. This underlines the caution which must be exercised in comparing blood lead data from different laboratories (Donovan et al., 1971; Berlin et al., 1972), and emphasises the importance of neither relying on blood lead alone as a screening measurement nor being too strict in the application of arbitrary limits.

The only unusual clinical feature in these subjects was clearly-described pleuritic pain. This is not classically associated with lead poisoning and the possibility of its being caused by cadmium was considered, since pleuritic chest pain and dyspnoea are recognised features of cadmium poisoning. Blood cadmium levels were not raised, however. Dagg et al. (1965) in a review of 50 cases of lead poisoning described non-abdominal pain in $50 \%$. This was mainly headache and limb pain, but discomfort in the chest and back also occurred. The cause of this is not known.

The absence of a relationship between measured biochemical changes and clinical state is perhaps not surprising in so small a group. Some biochemical measurements reflect lead exposure and absorption, for example blood lead; others reflect the degree of intoxication or effect, for example urinary ALA and erythrocyte protoporphyrin. Numerous studies have shown reasonable correlation between these different kinds of measurement (Waldron, 1971). In our group, lead excreted following chelation (chelatable lead) came just short of being significantly related to haemoglobin, urinary ALA or coproporphyrin and the same was true in comparing blood lead and haemoglobin.

When the symptom score is considered, however, it is found to approach a significant correlation with measurements of effect or toxicity (ALA and coproporphyrin in the urine: $\mathrm{r}=0.5 ; \mathrm{P}<0.1)$ but not with the index of exposure or absorption (blood lead: $r=$ $0.35 ; P>0.1)$. In spite of this, two subjects with normal urinary coproporphyrin, one of whom also had normal urinary ALA, were diagnosed as having lead poisoning on clinical grounds, supported by the discovery of depressed haemoglobin and elevated blood lead levels.

As far as selection for treatment is concerned, the presence of symptoms generally justifies chelation therapy. This may also be worthwhile where there is biochemical evidence of a severe degree of lead exposure even in the absence of symptoms because symptoms may develop subsequently, especially in two situations. First, a return to work involving further exposure to lead. Second, apparently any metabolic disturbance which may mobilise lead from its stores in bone.

The therapy chosen in this case was calcium disodium edetate. It was preferred to penicillamine in view of the possibility that these subjects had been exposed to cadmium. In animal studies penicillamine has been shown to produce marked histological change in the renal tubules in the presence of cadmium poisoning (Lyle et al., 1968). This effect has not been demonstrated in man. Calcium disodium edetate was given in a dose of $80 \mathrm{mg} / \mathrm{kg}$ body weight daily, and no toxic effects were encountered. It was noted, however, that following initial chelation therapy abdominal pain was sometimes brought on or worsened transiently. This effect was mitigated by intravenous calcium gluconate. The reason for the transient exacerbation of symptoms and the basis of the effectiveness of calcium salts in the relief of abdominal pain remains unclear.

One subject required transfusion because of a falling haemoglobin level. An incidental benefit of transfusion may be reversal of the stimulation of ALA synthase produced by anaemia. Increased ALA synthase activity in the face of a depressed ALA dehydrase increases the ALA level in the blood and soft tissues, and this may itself be harmful (McGillion et al., 1975; Becker et al., 1975). However, this theoretical consideration does not in itself constitute a case for transfusion.

The rapid reversal of the inhibiting effect of lead on some of the enzymes of the haem biosynthetic pathway following chelation therapy is reflected in the fall to normal levels of urinary ALA and coproporphyrin in three days of chelation. By contrast, haemoglobin and erythrocyte protoporphyrin were little affected in the short term. This is as expected, as these substances are principally found in the peripheral blood in mature red cells which already have their complement of haemoglobin and whose haem biosynthetic activity is low. These indices can be expected to return to normal only as cells formed in the post-treatment period become predominant in the blood.

Blood lead levels fell markedly with treatment but the best guide to the effectiveness of chelation is the quantity of lead excreted in the urine and this was satisfactory. Even this, however, leaves unanswered the question of how much lead is left behind, especially in the relatively inaccessible bone stores. 
This problem is illustrated by the subject who had few symptoms and a haemoglobin level of $12.9 \mathrm{~g} / \mathrm{dl}$ initially, with a blood lead level of only $4.0 \mu \mathrm{mol} / 1$ which, following the excretion of $148 \mu \mathrm{mol}$ of lead, fell to $2 \cdot 2 \mu \mathrm{mol} / 1$. Nevertheless, without any further exposure to lead, he subsequently developed fairly severe abdominal pain in the presence of a blood lead level of $5.8 \mu \mathrm{mol} / \mathrm{l}$.

Only two subjects have required more than one course of therapy; one because of continuing symptoms, elevated blood lead and anaemia; the other on the reappearance of symptoms. This latter case, however, together with the overall rise in blood lead levels in the group after one month, illustrates the need for follow-up. It also indicates that a return to work involving exposure to lead before three months following chelation is unwise. By that time lead levels should be consistently falling (Fig. 2) or another course of therapy will probably have been undertaken.

In this group, follow-up examinations will be continued as far as cooperation allows until the subjects are no longer exposed in lead-related industry, even though blood lead and haemoglobin levels may be normal.

\section{References}

Becker, D. M., Goldstuck, N., and Kramer, S. (1975). Effect of delta-aminolaevulinic acid on the resting membrane potential of frog sartorius muscle. South African Medical Journal, 49, 1790-1792.

Berlin, A., del Castilho, P., and Smeets, J. (1972). Paper 92, International Symposium, Environmental Health Aspects of Lead, Amsterdam.

Dagg, J. H., Goldberg, A., Lochhead, A., and Smith, J. A. (1965). The relationship of lead poisoning to acute intermittent porphyria. Quarterly Journal of Medicine, New Series 34, 163-175.

Donovan, D. T., Vought, V. N., and Rakow, A. B. (1971). Laboratories which conduct lead analyses on biologic specimens. Archives of Environmental Health, 23, 111-113.

Gibson, S. L. M., MacKenzie, J. C., and Goldberg, A. (1968). The diagnosis of industrial lead poisoning. British Journal of Industrial Medicine, 25, 40-51.

Lane, R. E. and 17 others (1968). The diagnosis of industrial lead poisoning: a statement. British Medical Journal, 4, 501.

Lyle, W. H., Green, J. N., Gore, V., and Vidler, J. (1968). Enhancement of cadmium nephrotoxicity by penicillamine in the rat. Postgraduate Medical Journal, Suppl., 44, 1821.

McGillion, F., Moore, M. R., and Goldberg, A. (1975). Some pharmacological effects of $\delta$-aminolaevulinic acid on blood pressure in the rat and on rabbit isolated ear arteries. Clinical and Experimental Pharmacology and Physiology, 2, 365-371.

Meredith, P. A., Moore, M. R., and Goldberg, A. (1977). Effects of aluminium, lead and zinc on $\delta$-aminolaevulinic acid dehydratase. Enzyme, 22, 22-27.

Waldron, H. A. (1971). Correlation between some parameters of lead absorption and lead intoxication. British Journal of Industrial Medicine, 28, 195-199.

Williams, M. K. (1966). Blood lead and haemoglobin in lead absorption. British Journal of Industrial Medicine, 23, $105-$ 111 